\title{
CHANGES INDUCED BY ESTRADIOL-ETHYLENEDIAMINE DERIVATIVE ON PERFUSION PRESSURE AND CORONARY RESISTANCE IN ISOLATED RAT HEART: L-TYPE CALCIUM CHANNEL
}

\author{
Lauro Figueroa-Valverde ${ }^{\mathrm{a} *}$, Francisco Diaz-Cedillo ${ }^{\mathrm{b}}$, Maria Lopez-Ramos ${ }^{\mathrm{a}}$, \\ Elodia Garcia-Cervera ${ }^{\mathrm{a}}$, Karen Quijano ${ }^{\mathrm{a}}$, Johani Cordoba ${ }^{\mathrm{a}}$
}

\begin{abstract}
a Laboratorio de Investigacion en Ciencias Biologicas y Farmacoqiímica de la Facultad de Ciencias Quimico-Biologicas, Universidad Autonoma de Campeche, Av. Agustin Melgar, Col Buenavista C.P.24039 Campeche Cam., Mexico

${ }^{b}$ Laboratorio de Quimica Organica de la Escuela Nacional de Ciencias Biologicas del Instituto Politecnico Nacional. Prol. Carpio y Plan de Ayala s/n Col. Santo Tomas C.P. 11340, Mexico, D.F.

E-mail: lauro_1999@yahoo.com
\end{abstract}

Received: December 10, 2010; Accepted: February 9, 2011

Key words: Estradiol-ethylenediamine/Perfusion pressure/Coronary resistance/L-type calcium channel

Aim. The present study was designed to investigate the effects of estradiol-ethylenediamine derivative on perfusion pressure and coronary resistance in rats. An additional aim was to identify the molecular mechanisms involved.

Methods. The Langendorff model was used to measure perfusion pressure and coronary resistance changes in isolated rat heart after estradiol-ethylenediamine derivative alone and following compounds; tamoxifen (estrogen receptor antagonist), prazosin (alpha1 adrenoreceptor antagonist), metoprolol (selective beta1 receptor blocker), indomethacin (prostanglandin synthesis inhibitor) and nifedipine (L-type calcium-channel inhibitor).

Results. The results show that estradiol-ethylenediamine derivative $\left[10^{-9} \mathrm{mmol}\right]$ significantly increased perfusion pressure $(p=0.005)$ and coronary resistance $(p=0.006)$ in isolated rat heart. Additionally, the effect of estradiolethylenediamine on perfusion pressure $\left[10^{-9}\right.$ to $\left.10^{-4} \mathrm{mmol}\right]$ was only blocked in the presence of the L-type calciumchannel (nifedipine).

Conclusions. These data suggest that the effect of estradiol-ethylenediamine on perfusion pressure and vascular coronary involves activation of the L-type calcium channel through a non-genomic molecular mechanism.

\section{INTRODUCTION}

High blood pressure contributes substantially to cardiovascular disease incidence and premature mortality $^{1-3}$. Studies monitoring ambulatory blood pressure have shown that blood pressure is higher in men than in women of similar age ${ }^{4,5}$. In addition, experimental and clinical studies ${ }^{6-8}$ have demonstrated that sex hormones may be associated with hypertension. Further, sex differences in blood pressure regulation in humans have also been demonstrated in various animal models ${ }^{9-11}$. For example, male spontaneously hypertensive rats (SHR) have higher blood pressure than do females of similar age ${ }^{12-14}$. These data suggest that among others, estrogen levels may influence blood pressure. In this regard, there is evidence that estrogen replacement in ovariectomized rats reduces arterial pressure response to psychological stress and that these effects are mediated, at least in part by nitric oxide ${ }^{15}$. In addition, estrogens have been shown to protect transgenic hypertensive rats by shifting the vasoconstrictorvasodilator balance of the renin-angiotensin system and consequently induce change in blood pressure ${ }^{16}$.

There are also studies which suggest that some estradiol derivatives also induce changes in blood pressure as well; for example, Bonacasa et $\mathrm{al}^{17}$., reported indicate that estradiol derivative (2-methoxyestradiol) attenuates hypertension in spontaneously hypertensive rats while 2-hydroxyestradiol was found to reduce blood pressure in an obese rat mode ${ }^{18}$. The molecular mechanism of these two estradiol derivatives involves inhibition of endothelin-1 synthesis by means of an estrogen receptorindependent mechanism ${ }^{19}$. These data taken together show that estradiol and its derivatives induce changes in blood pressure; nevertheless, the cellular site and molecular mechanisms involved are very confusing. Differences in the chemical structure of estradiol and its derivatives may be in part responsible. To test this, the present study was designed to investigate the effects of an estradiol derivative on perfusion pressure and coronary resistance in isolated rat hearts using the Langendorff model. To evaluate the molecular mechanisms involved, the following compounds were used as pharmacological tools for blocking various receptors; tamoxifen (estrogen receptor antagonist) (ref. $\left.{ }^{20}\right)$, prazosin ( $\alpha_{1}$ adrenoreceptor antagonist) (ref. ${ }^{21}$ ), metoprolol (selective $\beta_{1}$ receptor blocker) (ref. ${ }^{22}$ ), indomethacin (prostaglandin synthesis inhibitor) (ref. ${ }^{23}$ ) and nifedipine (L-type calcium-channel inhibitor) $\left(\right.$ ref. $\left.^{24}\right)$. 


\section{MATERIAL AND METHODS}

\section{General methods}

All experimental procedures and protocols used in this investigation were reviewed and approved by the Animal Care and Use Committee of Universidad Autonoma de Campeche (UAC) and were in accordance with the Guide for the Care and Use of Laboratory Animals

(Washington, DC: National Academy Press, 1996) (ref. ${ }^{25}$ ). Female rats (Wistar; weighing 200-250 g) were obtained from UAC.

\section{Reagents}

Estradiol-ethylenediamine derivative (Fig. 1) was prepared according to a previously reported method by Figueroa et al. ${ }^{26}$. Other reagents were obtained from Sigma-Aldrich Chemical Co. All drugs were dissolved in methanol and different dilutions were obtained using Krebs-Henseleit solution $(\leq 0.01 \%, v / v)$.

\section{Langendorff method.}

Briefly, the female rat (200-250 g) was anesthetized by injection with pentobarbital at a dose rate of $50 \mathrm{mg} /$ $\mathrm{kg}$ body weight. The chest was then opened, and a loose ligature passed through the ascending aorta. The heart was rapidly removed and immersed in ice cold physiological saline solution. It was trimmed of non-cardiac tissue and retrograde perfused via a non-circulating perfusion system at a constant flow rate. The perfusion medium was

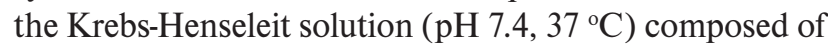
(mmol); $117.8 \mathrm{NaCl} ; 6 \mathrm{KCl} ; 1.75 \mathrm{CaCl}_{2} ; 1.2 \mathrm{NaH}_{2} \mathrm{PO}_{4} ; 1.2$ $\mathrm{MgSO}_{4} ; 24.2 \mathrm{NaHCO}_{3} ; 5$ glucose, and 5 sodium pyruvate. The solution was actively bubbled with a mixture of $\mathrm{O}_{2} /$ $\mathrm{CO}_{2}$ (95:5). The coronary flow was adjusted with a variable-speed peristaltic pump. An initial perfusion rate of 15 $\mathrm{ml} / \mathrm{min}$ for $5 \mathrm{~min}$ was followed by a 25 min equilibration period at a perfusion rate of $10 \mathrm{ml} / \mathrm{min}$. All experimental measurements were made after the equilibration period.

\section{Perfusion pressure}

Evaluations of perfusion pressure changes due to drugs were made using a pressure transducer connected to

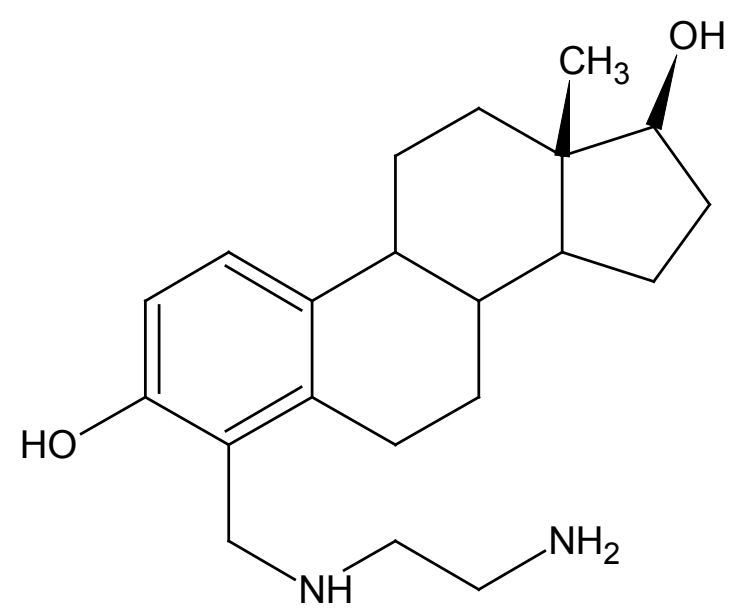

Fig. 1. Chemical structure of estradiol derivative. the chamber where the hearts were mounted. The results were entered into a computerized data capture system (Biopac).

\section{Experimental design}

Eighteen animals were used, 9 for both control and treatment groups. The control group received no drug while the treatment group functioned as its own control

Effect of estradiol-ethylenediamine derivative on perfusion pressure. Changes in perfusion pressure as a consequence of increase in time (3-18 $\mathrm{min})$ in the absence (control) or presence of estradiol-ethylenediamine derivative at a concentration of $10^{-9} \mathrm{mmol}$ were determined. The effects were obtained in isolated hearts perfused at a constant-flow rate of $10 \mathrm{ml} / \mathrm{min}$.

Effects of estradiol-ethylenediamine derivative on coronary resistance. Coronary resistance in the absence (control) or presence of estradiol-ethylenediamine derivative at a concentration of $10^{-9} \mathrm{mmol}$ was evaluated. The effects were obtained in isolated hearts perfused at a constant flow rate of $10 \mathrm{ml} / \mathrm{min}$. The coronary resistance was determined as the relationship between coronary flow and perfusion pressure $(\mathrm{mm} \mathrm{Hg} / \mathrm{ml} / \mathrm{min}$ ).

Effects of estradiol-ethylenediamine derivative on perfusion pressure through the estrogen receptors. Intracoronary boluses $(50 \mu \mathrm{l})$ of estradiol-ethylenediamine derivative [ $10^{-9}$ to $\left.10^{-4} \mathrm{mmol}\right]$ were administered and the corresponding effect on perfusion pressure was determined. The dose-response curve (control) was re-determined in the presence of tamoxifen at a concentration of $10^{-6}$ mmol (duration of preincubation with tamoxifen was by a 10 min equilibration period).

Effect of estradiol-ethylenediamine derivative on perfusion pressure through the $\alpha_{1}$ adrenergic receptor. Intracoronary boluses $(50 \mu \mathrm{l})$ of estradiol-ethylenediamine derivative [ $10^{-9}$ to $\left.10^{-4} \mathrm{mmol}\right]$ were administered and the corresponding effect on perfusion pressure was evaluated. The dose-response curve (control) was determined in the presence of prazosin at a concentration of $10^{-6} \mathrm{mmol}$ (duration of preincubation with prazosin was a $10 \mathrm{~min}$ equilibration period).

Effects of estradiol-ethylenediamine derivative on perfusion pressure through the $\beta_{1}$ adrenergic receptor. Intracoronary boluses $(50 \mu \mathrm{l})$ of estradiol-ethylenediamine derivative $\left[10^{-9}\right.$ to $\left.10^{-4} \mathrm{mmol}\right]$ were administered and the corresponding effect on the perfusion pressure was evaluated. The dose-response curve (control) was again obtained in the presence of metoprolol at concentration of $10^{-6} \mathrm{mmol}$ (duration of preincubation with metoprolol was by a 10 min equilibration period).

Changes induced by estradiol-ethylenediamine derivative on perfusion pressure through synthesis of prostanglandins. Intracoronary boluses $(50 \mu \mathrm{l})$ of estradiol-ethylenediamine derivative $\left(10^{-9}\right.$ to $\left.10^{-4} \mathrm{mmol}\right)$ were administered and the corresponding effect on the perfusion pressure was evaluated. The dose-response curve (control) was determined in the presence of indomethacin at a concentration of $10^{-6}$ mmol (duration of preincubation with indomethacin was a 10 min equilibration period). 


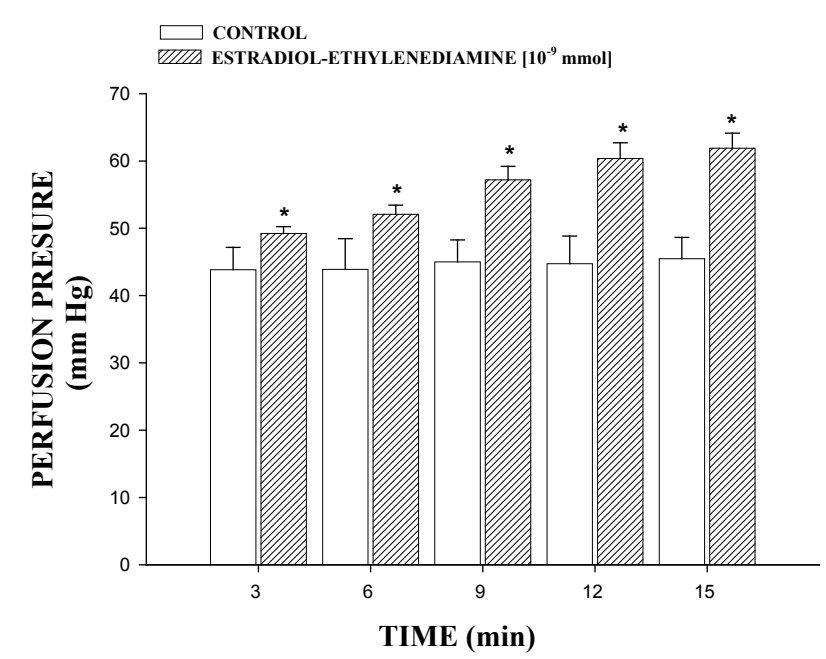

Fig. 2. Effect induced by estradiol derivative on perfusion pressure. The results show that estradiol derivative $\left[10^{-9} \mathrm{mmol}\right]$ significantly increased perfusion pressure $(p=0.005)$ through time $(3-18 \mathrm{~min})$ in comparison with the control conditions. Each bar represents the mean \pm S.E. of 9 experiments.

- ESTRADIOL-ETHYLENEDIAMINE

O ESTRADIOL-ETHYLENEDIAMINE + TAMOXIFEN $\left[10^{-6} \mathrm{mmol}\right]$

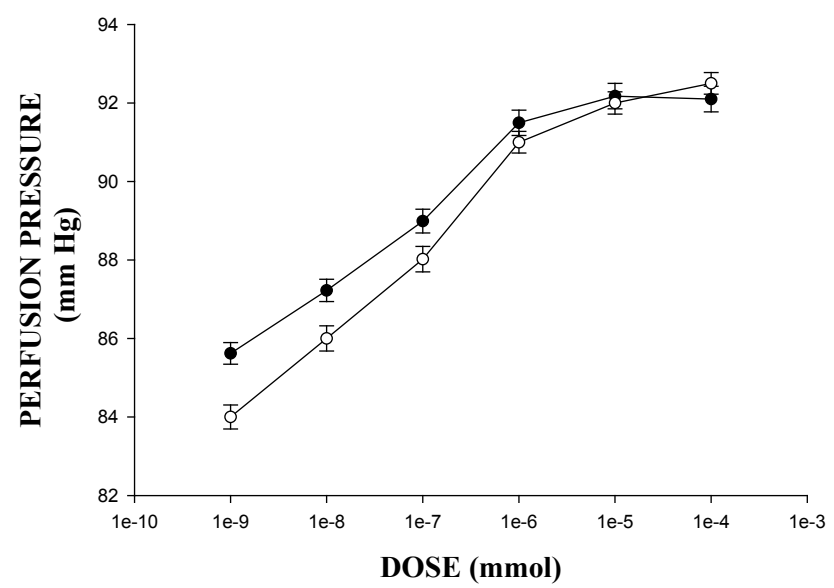

Fig. 4. Effects induced by estradiol derivative on perfusion pressure through estrogen receptors. Intracoronary boluses $(50 \mu \mathrm{l})$ of estradiol derivative $\left[10^{-9}\right.$ to $\left.\left.10^{-4} \mathrm{mmol}\right]\right)$ were administered and the corresponding effect on the perfusion pressure was determined. The results showed that estradiol derivative increase the perfusion pressure in a dependent dose manner and this effect was not inhibited in presence of tamoxifen $\left[10^{-6}\right.$ mmol]. Each bar represents the mean \pm S.E. of 9 experiments.

Effects of estradiol-ethylenediamine derivative on perfusion pressure through the calcium channel. Intracoronary boluses $(50 \mu \mathrm{l})$ of estradiol-ethylenediamine derivative [ $10^{-9}$ to $\left.10^{-4} \mathrm{mmol}\right]$ were administered and the corresponding effect on the perfusion pressure was evaluated.

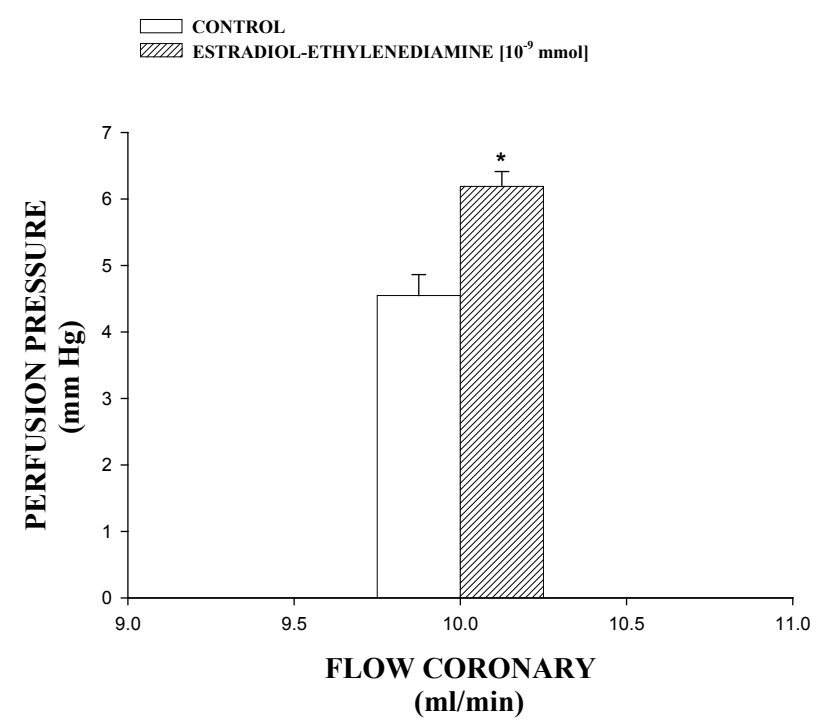

Fig. 3. Activity exerted by estradiol derivative on coronary resistance. The results show that coronary resistance was higher $(p=0.006)$ in the presence of estradiol derivative $\left[10^{-9} \mathrm{mmol}\right]$ in comparison with the control conditions. Each bar represents the mean \pm S.E. of 9 experiments.

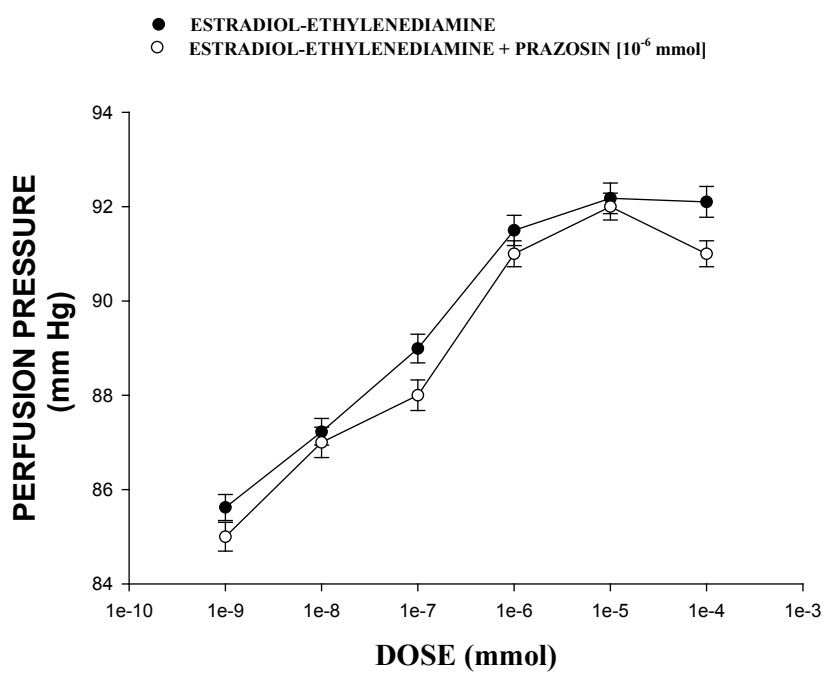

Fig. 5. Effect exerted by estradiol derivative on perfusion pressure through of $\alpha_{1}$ adrenergic receptor. Estradiol derivative [ $10^{-9}$ to $\left.10^{-4} \mathrm{mmol}\right]$ was administered (intracoronary boluses, $50 \mu \mathrm{l}$ ) and the corresponding effect on the perfusion pressure was evaluated in absence and presence of prazosin $\left[10^{-6} \mathrm{mmol}\right]$. The results showed that activity induced by estradiol derivative on perfusion pressure was not inhibited in presence of prazosin. Each bar represents the mean \pm S.E. of 9 experiments.

The dose-response curve (control) was obtained in the presence of nifedipine at a concentration of $10^{-6} \mathrm{mmol}$ (duration of preincubation with nifedipine was a $10 \mathrm{~min}$ equilibration period). 


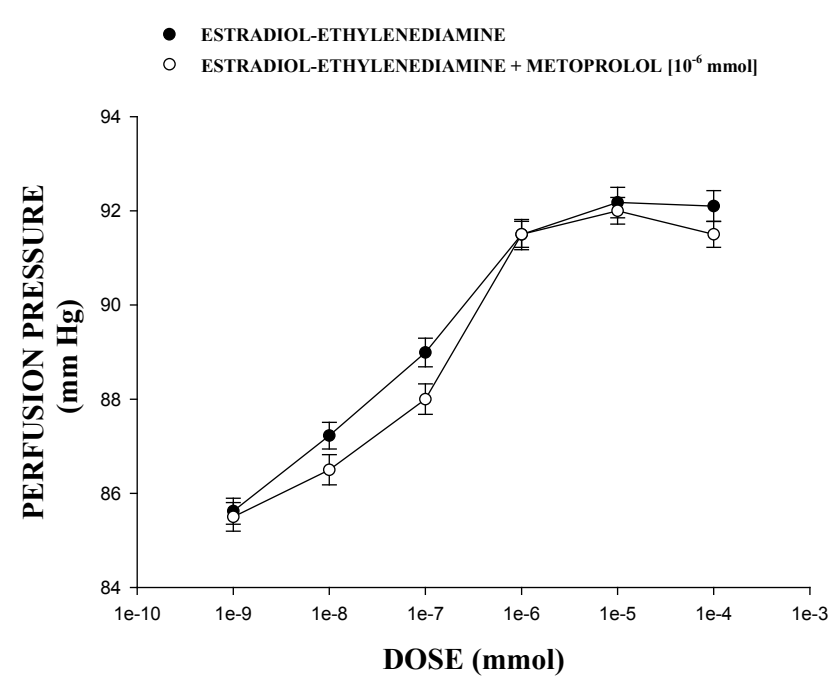

Fig. 6. Activity induced by estradiol derivative on perfusion pressure through of $\beta$ - adrenergic receptor. Intracoronary boluses $(50 \mu \mathrm{l})$ of estradiol derivative $\left[10^{-9}\right.$ to $\left.10^{-4} \mathrm{mmol}\right]$ were administered and the corresponding effect on the perfusion pressure was evaluated in absence and presence of metoprolol (10-6 mmol). The results showed that activity induced by estradiol derivative on perfusion pressure was not inhibited in presence of metoprolol. Each bar represents the mean \pm S.E. of 9 experiments.

\section{Statistical analysis}

The results are expressed as means $\pm \mathrm{SE}$, using each heart as its own control. The data were analyzed using analysis of variance repeated measures (ANOVA) and the Bonferroni correction factor ${ }^{27}$. The differences were considered significant when $p$ was equal to or smaller than 0.05 .

\section{RESULTS}

Changes in perfusion pressure as a consequence of increase in time (3-18 $\mathrm{min}$ ) in the absence (control) or presence of estradiol-ethylenediamine derivative (Fig. 2) were evaluated. The results showed that estradiol derivative $\left[10^{-9} \mathrm{mmol}\right]$ significantly increased the perfusion pressure $(p=0.005)$ in comparison with the control. (Fig. 3) shows that coronary resistance calculated as the ratio of perfusion pressure at the coronary flow assayed $(10 \mathrm{ml} / \mathrm{min})$ was higher $(p=0.006)$ in the presence of estradiol-ethylenediamine derivative $\left[10^{-9} \mathrm{mmol}\right]$ than in controls. (Fig. 4) shows that estradiol-ethylenediamine derivative, increased the perfusion pressure in a dose dependent manner [ $10^{-9}$ to $\left.10^{-4} \mathrm{mmol}\right]$ and that this effect was not inhibited by tamoxifen $\left[10^{-6} \mathrm{mmol}\right]$.

The effect of estradiol-ethylenediamine derivative $\left[10^{-9}\right.$ to $10^{-4} \mathrm{mmol}$ ] on perfusion pressure in the presence of prazosin (Fig. 5) or metoprolol (Fig. 6) at a concentration of $10^{-6} \mathrm{mmol}$ was not inhibited. (Fig. 7) shows that

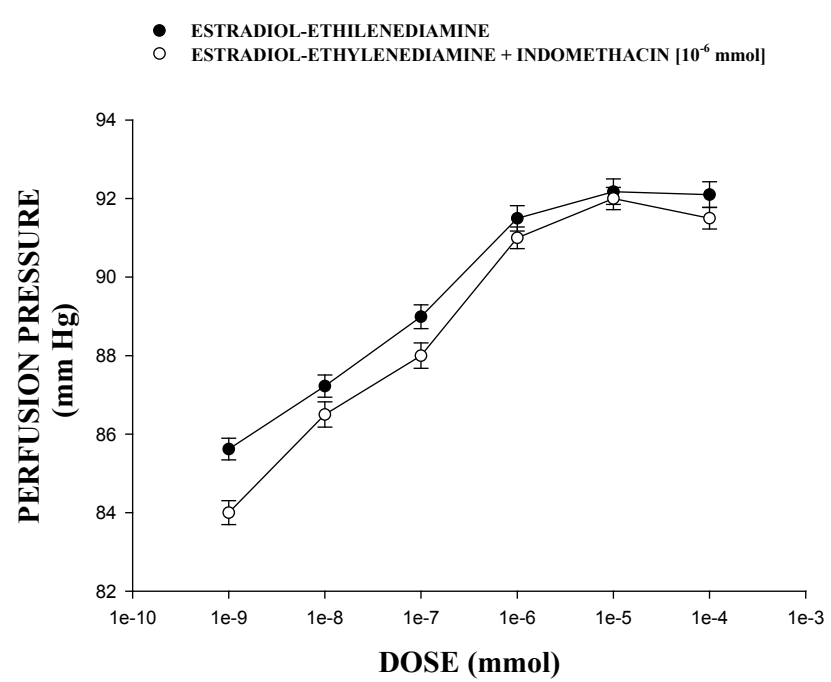

Fig. 7. Effects induced by estradiol derivative on perfusion pressure through of synthesis of prostanglandins. Intracoronary boluses $(50 \mu \mathrm{l})$ of estradiol derivative $\left[10^{-9}\right.$ to $\left.10^{-4} \mathrm{mmol}\right]$ were administered in absence and presence of indomethacin $\left[10^{-6}\right.$ $\mathrm{mmol}]$.The results showed that effect induced by estradiol derivative on perfusion pressure in presence of indomethacin was not inhibited. Each bar represents the mean \pm SE of 9 experiments.

- ESTRADIOL-ETHYLENEDIAMINE

O ESTRADIOL-ETHYLENEDIAMINE + NIFEDIPINE $\left[10^{-6} \mathrm{mmol}\right]$

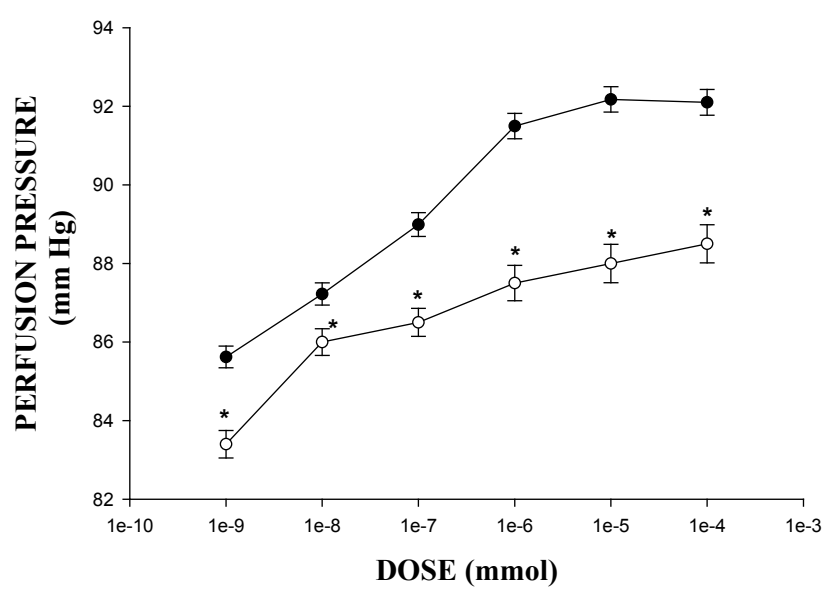

Fig. 8. Activity exerted by estradiol derivative on perfusion pressure through L- type calcium channel. Intracoronary boluses $(50 \mu \mathrm{l})$ of estradiol derivative $\left[10^{-9}\right.$ to $\left.10^{-4} \mathrm{mmol}\right]$ were administered in absence and presence of nifedipine $\left[10^{-6} \mathrm{mmol}\right]$. The results showed that effect induced by estradiol derivative on perfusion pressure in presence of nifedipine was inhibited significantly $(p=0.005)$. Each bar represents the mean \pm SE of 9 experiments. 
the effect of estradiol-ethylenediamine derivative $\left[10^{-9}\right.$ to $10^{-4} \mathrm{mmol}$ ] on perfusion pressure was not blocked by indomethacin $\left[10^{-6} \mathrm{mmol}\right]$. Finally, the effect of estradiolethylenediamine derivative $\left[10^{-9}\right.$ to $\left.10^{-4} \mathrm{mmol}\right]$ on perfusion pressure in the presence of nifedipine (Fig. 8) was significantly inhibited $(p=0.005)$.

\section{DISCUSSION}

In this study, were evaluated the effect of estradiolethylenediamine derivative on blood vessel capacity and coronary resistance translated as changes in perfusion pressure in isolated rat heart (Langendorff model). The results show that estradiol-ethylenediamine derivative significantly increased perfusion pressure over time (3-18 min) compared to the controls. These data suggest that estradiol-ethylenediamine derivative exerts effects on perfusion pressure, which could subsequently modify vascular tone and coronary resistance. To test this hypothesis, we evaluated the effects induced by estradiol-ethylenediamine derivative on coronary resistance. We found that coronary resistance was increased by the estradiol-ethylenediamine derivative. These data suggest that estradiolethylenediamine derivative exerts effect on vascular tone.

To characterize the molecular mechanism of this phenomenon we noted the reports of some investigations ${ }^{28-30}$ which indicate that estradiol induces its effect on blood pressure via activation of the estrogen receptor. For this reason, we used tamoxifen, a estrogen receptor blocker to determine if the effects of estradiol-ethylenediamine derivative on perfusion pressure were via the estrogen receptor. Interaction of estradiol-ethylenediamine derivative with the estrogen-receptor, may be a key requirement for the biological activity as in the case of other estradiol derivatives ${ }^{31,32}$. Our results showed that the effects of estradiol-ethylenediamine derivative were not inhibited by tamoxifen, suggesting that the molecular mechanism is not via the estrogen-receptor.

On the other hand, the molecular mechanism proposed by some investigators ${ }^{33}$ suggests that estradiol can exert an indirect tonic effect on adrenal catecholamine synthesis. Some studies report that estradiol decreases norepinephrine levels and consequently induces low blood pressure ${ }^{34,35}$. To evaluate the biological activity of estradiol-ethylenediamine derivative on perfusion pressure in the absence or presence of prazosin ( $\alpha_{1}$ adrenoreceptor antagonist) and metoprolol (selective $\beta_{1}$ receptor blocker) was evaluated. Our results showed that the effect of estradiol-ethylenediamine derivative was not inhibited by these compounds, indicating that the molecular mechanism involved is not through adrenergic activity.

Some steroids ${ }^{36}$ have been found to exert effects on perfusion pressure via-prostanglandins stimulation and secretion. For this reasons we used the prostanglandins synthesis inhibitor indomethacin to test this concept. The results showed that indomethacin did not block the effects of estradiol-ethylenediamine derivative, suggesting that mechanism was not via prostanglandins synthesis and secretion. Analyzing these data and reports indicat- ing that the effect of a number of steroids on blood pressure involves activation of the calcium channel ${ }^{37}$, we used nifedipine an L-type calcium channel inhibitor. The results showed that the activity of estradiol-ethylenediamine derivative was significantly blocked by nifedipine.

The results suggest that the effect of estradiol derivate on perfusion pressure may be to increase calcium levels through activation of the L-type calcium channel via a non-genomic molecular mechanism. This explanation is similar to explanations for the effect of some steroid derivatives on perfusion pressure involveing increase in intracellular calcium through a non-genomic mechanism ${ }^{38,39}$.

\section{CONCLUSIONS}

Overall, the results suggest that the effect of estradiolethylenediamine derivative on perfusion pressure and coronary resistance is dependent on its chemical structure and may involve the L-type calcium channel activation through a non-genomic molecular mechanism.

\section{ACKNOWLEDGEMENT}

Dr. Figueroa Valverde L. is grateful to Victor Rivera and Rubi Marin for their technical assistance.

\section{REFERENCES}

1. Stary HC. Evolution and progression of atherosclerotic lesions in coronary arteries of children and young adults. Arteriosclerosis 1986;9:119-32.

2. Mahoney L, Burns T, Stanford W. Coronary risk factors measured in childhood and young adult life is associated with coronary artery calcification in young adults. J Am Coll Cardiol 1996;27:277-84.

3. Oparil S, Zaman A, Calhoun A. Pathogenesis of hypertension. Ann Intern Med 2003;139:761-76.

4. Khoury S, Yarows SA, O'brien TK, Sowers JR. Ambulatory blood pressure monitoring in a nonacademic setting: Effects of age and sex. Am J Hypertens 1992;5:616-23.

5. Wiinberg N, Hoegholm A, Christensen HR, Bang LE, Mikkelsen KL, Nielsen P. 24-h Ambulatory blood pressure in 352 normal Danish subjects, related to age and gender. Am J Hypertens 1995;8:978-86.

6. Khaw K, Barrett-Connor E. Blood pressure and endogenous testosterone in men: an inverse relationship. J Hypertens 1988;6:32932.

7. Gray A, Berlin J, Mckinlay J, Longcope C. An examination of research design effects on the association of testosterone and male aging: results of a meta-analysis. J Clin Epidemiol 1991;44:671-84.

8. Gray A, Feldman H, Mckinlay J, Longcope C. Age, disease, and changing sex hormone levels in middle-aged men: Results of the Massachusetts Male Aging Study. J Clin Endocrinol Metab 1991;73:1016-25.

9. Ouchi Y, Share L, Crofton JT, Iitake K, Brooks DP. Sex difference in the development of deoxycorticosterone-salt hypertension in the rat. Hypertension 1987;9:172-7.

10. Ashton N, Balment RJ. Sexual dimorphism in renal function and hormonal status of New Zealand genetically hypertensive rats. Acta Endocrinol (Copenh) 1991;124:91-7.

11. Rowland NE, Fregly MJ. Role of gonadal hormones in hypertension in the Dahl salt-sensitive rat. Clin. Exp. Hypertens 1992;A14:367-75. 
12. Masubuchi Y, Kumai T, Uematsu A, Komoriyama K, Hirai M. Gonadectomy-induced reduction in blood pressure in adult spontaneously hypertensive rats. Acta Endocrinol 1982;101:154-60.

13. Chen Y, Meng Q. Sexual dimorphism of blood pressure in spontaneously hypertensive rats is androgen dependent. Life Sci 1991;48: 85-96.

14. Reckelhoff J, Zhang H, Granger J. Testosterone Exacerbates Hypertension and Reduces Pressure-Natriuresis in Male Spontaneously Hypertensive Rats. Hypertens 1998;431:35.

15. Cherney A, Edgell H, Krukoff T. NO mediates effects of estrogen on central regulation of blood pressure in restrained, ovariectomized rats. Am J Physiol Regul Integr Comp Physiol 2003;285: R842-9.

16. Brosnihan KB, Li P, Ganten D, Ferrario C. Estrogen protects transgenic hypertensive rats by shifting the vasoconstrictor-vasodilator balance of RAS. AJP-Reg Int Comp Physiol 1997;273:1908-15.

17. Bonacasa B, Sanchez M, Rodriguez F, Lopez B, Quesada T, Fenoy F, Hernández I. 2-Methoxyestradiol attenuates hypertension and coronary vascular remodeling in spontaneously hypertensive rats. Maturitas 2008;61;1:310-6.

18. Tofovic SP, Dubey RK, Jackson EK. 2-Hydroxyestradiol attenuates the development of obesity, the metabolic syndrome, and vascular and renal dysfunction in obese ZSF1 rats. J Pharmacol Exp Ther 2001;299:973-7.

19. Dubey RK, Jackson E, Keller P, Imthurn B, Rosselli M. Estradiol Metabolites Inhibit Endothelin Synthesis by an Estrogen ReceptorIndependent Mechanism. Hypertens 2001;37:640-4.

20. Shiau A, Barstad D, Loria P, Cheng L, Kushner P, Agard D, Greene G. The Structural Basis of Estrogen Receptor/Coactivator Recognition and the Antagonism of This Interaction by Tamoxifen Cell 1998;95:927-37.

21. Graham R, Oates H, Stoker L, Stokes G. Alpha blocking action of the antihypertensive agent, prazosin. J Pharmacol Exper Ther 1977;201:747-52.

22. Bengtsson C, Johnsson G, Regårdh CG. Plasma levels and effects of metoprolol on blood pressure and heart rate in hypertensive patients after an acute dose and between two doses during long-term treatment. Clin Pharmacol Ther 1975;17:400-8.

23. Owen T, Ehrhart I, Weidner W, Scott J, Haddy F. Effects of indomethacin on local blood flow regulation in canine heart and kidney. Exp Biol Med 1975;149:871-6.

24. Henry PD. Comparative pharmacology of calcium antagonists nifedipine, verapamil and diltiazem. Am J Cardiol 1980;46:104758 .

25. Institute of Laboratory Animal, Resources Commission on Life Sciences, National Research Council. Guide for the care and use of laboratory animals. Seventh edition, Washington, D.C.: National Academies Press; 1996. p. 1-240.

26. Figueroa-Valverde L, Díaz-Cedillo F, López-Ramos M, GarcíaCervera E. Synthesis of Amino-Estradiol Derivative: Relationship with the Physicochemical Descriptors $\log \mathrm{P}, \pi, \mathrm{R}_{\mathrm{m}}, \mathrm{V}_{\mathrm{m}}, \mathrm{P}_{\mathrm{c}}$ and $\mathrm{S}_{\mathrm{t}}$. Asian J Chem 2011;23(5):2157-2161.

27. Hocht C, Opezzo J, Gorzalczany S, Bramuglia G, Tiara C. Una aproximación cinética y dinámica de metildopa en ratas con coartación aórtica mediante microdiálisis. Rev Argent Cardiol 1999;67:769-73.

28. Horwitz K, McGuires W. Nuclear Mechanisms of Estrogen Action. Effects of estradiol and anti-estrogens on estrogens receptors and nuclear receptor processing. J Biol Chem 1978;253:8185-91.

29. Karas RH, Patterson BL, Mendelsohn ME. Human vascular smooth muscle cells contain functional estrogen receptor. Circulation 1994;89:1943-50.

30. Mahmoodzadeh S, Fritschka S, Dworatzek E, Pham T, Becher E, Kuehne A, Davidson M, Regitz-Zagrosek V. Nuclear Factor- $\kappa$ B Regulates Estrogen Receptor- $\alpha$ Transcription in the Human Heart. J Biol Chem 2009;284:24705-14.

31. Haynes MP, Sinha E, Russell K, Collinge M, Fulton D, MoralesRuiz M, Sessa W, Bender J. Membrane Estrogen Receptor Engagement Activates Endothelial Nitric Oxide Synthase via the PI3-Kinase-Akt Pathway in Human Endothelial Cells. Circ Res 2000;87:677-82

32. Kaspar P, Witzel H. Steroid binding to the cytosolic estrogen receptor from rat uterus. influence of the orientation of substituents in the 17-position of the $8 \beta$ - and $8 \alpha$-series. J Steroids Biochem 1985;23:259-65.

33. Hamlet MA, Rorie DK, Tyce GM. Effects of estradiol on release and disposition of norepinephrine from nerve endings. Am J Physiol 1980;239:H450-6.

34. Sudhir K, Esler; Garry K, Jennings L, Komesaroff P. Estrogen Supplementation Decreases Norepinephrine-Induced Vasoconstriction and Total Body Norepinephrine Spillover in Perimenopausal Women. Hypertens 1997;30:1538-43.

35. Peng N, Clark JT, Wei C, Wyss JM. Estrogen Depletion Increases Blood Pressure and Hypothalamic Norepinephrine in Middle-Aged Spontaneously Hypertensive Rats. Hypertens 2003;41:1164-67.

36. Seillan C, Ody C, Russo F, Duval D. Differential aspects of sex steroids on prostaglandin secretion by male and female cultured piglet endothelial cells. Prostaglandins 1983;26:3-12.

37. Figueroa L, Díaz F, Camacho A, Díaz E, Marvin R. Actividad inducida por androsterona y hemisuccinato de androsterona sobre la presión de perfusión y la resistencia vascular. Biomedica 2009;29:625-34.

38. Ceballos G, Figueroa L, Rubio I, García A, Martínez A, Yañez R. Acute and nongenomic effects of testosterone on isolated and perfused rat heart. J Cardiovasc Pharmacol 1999;33:691-7.

39. Figueroa-Valverde L, Díaz-Cedillo F, Diaz-Ku E, Camacho-Luis A. Effect induced by hemisuccinate of pregnenolone on perfusion pressure and vascular resistance in isolated rat heart. African J Pharm Pharmacol 2009;3:234-41. 